\title{
Examining Preservice Teachers' Self-Efficacy for Enhancing Literacy of Diverse Learners through Music
}

\author{
Nancy McBride Arrington ${ }^{a}$
}

${ }^{a}$ Department of Teaching and Learning, Georgia Southern University, United States

\begin{abstract}
The sense of efficaciousness for teaching diverse learners was examined with twenty-four pre-service teachers concurrently enrolled in a junior-level Creative Arts methods course and a field experience course with placements in $\mathrm{K}-2$ general education classrooms. The pre-service teachers participated in music and literacy activities in their university class, then planned and implemented standards-based music activities in literacy lessons with their young students. Both quantitative and qualitative data were collected, including a teacher self-efficacy scale, an attitude survey, written reflections, interviews, open-ended responses, and lesson plans. Results demonstrated a significant increase in the pre-service teachers' self-efficacy in pre-post ratings analysis and indicated that this project contributed to their efficacy for meeting needs of diverse learners in the elementary classrooms. The preservice teachers demonstrated proactive classroom management and reflected upon their students' increased focus in class. The pre-service teachers indicated that their success with these types of projects encouraged them to plan for similar implementation with their future diverse learners, potentially contributing to a positive impact on their future performance. Additionally, this project emanated Scholarship of Teaching and Learning by encouraging self-reflection; examining and applying effective teaching strategies; and advancing the field of teacher education.
\end{abstract}

Keywords: Self-Efficacy, Diverse Learners, Music Integration, Scholarship of Teaching and Learning 


\section{Introduction}

Teacher preparation programs are challenged with equipping their candidates with the tools necessary for coping with the encounters, such as meeting needs of diverse learners, they will face throughout their practicum experiences and as they begin teaching in their own classrooms. Using music activities is one way to involve diverse learners in lessons, and the use of music has benefits that contribute to literacy development in young students. According to the Common Core State Standards Initiative (CCSS, 2012), literacy instruction is the responsibility of all content areas, which includes music education. Similar themes are shared between CCSS for English Language Arts (ELA) and the National Standards for Music Education (NAfME, 2014). Some of the commonalities and correlations between literacy and music education include demonstrating independence, having strong content knowledge, comprehending, critiquing, understanding other perspectives and cultures, phonological awareness, auditory discrimination, sight identification, orthographic awareness, fluency, and interdisciplinary connections of concepts through music (Coleman, n.d.; Hansen \& Bernstorf, 2002; Isbell \& Raines, 2013; Paquette \& Reig, 2008; Weidner, 2013). Bernstorf (2013) reminds us that good music literacy can "provide the very same benefits as those who teach language reading, plus the enjoyment of an arts experience" (p. 2).

Identifying and addressing the needs of diverse learners has been cited as a weakness by the preservice teachers in our early childhood education program. During a recent study, those in the junior-level practicum frequently pinpointed the following two diversities as the most challenging in their Kindergarten through second grade English Language Arts (ELA) classes: attention or focus, and auditory processing (Arrington \& Lu, 2015). Noting these weaknesses, it is important to provide opportunities for pre-service teachers to increase their efficacy for meeting the needs of their diverse learners. Bandura (1997), offers "Perceived self-efficacy refers to beliefs in one's capabilities to organize and execute the courses of action required to produce given attainments" (p. 3). Perceived self-efficacy is not concerned with the amount of skill one has, but what he/she believes can be done with what he/she has in given circumstances. Bandura further asserts that experiences (referred to as Enactive Mastery Experiences) have the most influence on self-efficacy.

This project developed from a desire by the instructor of the Creative Arts methods course to enrich Early Childhood Education pre-service teachers' practicum experience, ultimately leading to success in their future classrooms. The instructor's goals in this project include (a) equipping them with skills gained from the Creative Arts class that can be applied in their ELA lessons with their young children, (b) providing them a potentially richer and more meaningful field experience through integration of the arts, (c) eliciting a more critical level of self-reflection, and (d) stimulating a higher sense of efficaciousness as they address the challenge of meeting the needs of diverse learners. This project emanates 
Hutchings and Cambridge's (1999) definition of Scholarship of Teaching and Learning (SoTL): “...problem posing about an issue of teaching or learning, study of the problem through methods appropriate to disciplinary epistemologies, applications of results to practice, communication of results, self-reflection, and peer review" (p.7). Finally, Gardner (1993) posits that musical intelligence develops early in children; therefore, it is reasonable to introduce music-based activities to future teachers of early childhood classrooms.

\section{Methods}

\subsection{Participants and Procedures}

The participants in this study included twenty-four second-semester junior Early Childhood Education (ECED) pre-service teachers enrolled in a Creative Arts Methods Course. The course is taught by a former elementary music specialist/national board certified music teacher. The pre-service students participated in the creative arts activities during their university class, and planned/implemented instructor-approved, standards-based music activities with literacy lessons during their concurrent field experience course in assigned Kindergarten, first, or second grade classrooms. They completed pre- and post- selfefficacy scale ratings at the beginning and end of the course. Throughout the semester, they submitted self-reflections and ratings based on their experience and attitude toward their class participation, lesson planning, and implementation of the activities in their practicum classrooms.

\subsection{Methodology}

Multiple methods were used for data collection and analysis in this study. Quantitative data consisted of the Teacher Self-Efficacy Scale (Bandura, 2006) as a pre- and post-test measurement; a beginning and endpoint Likert rating scale which contains five items from the Teacher Self-Efficacy Scale directly related to addressing diverse learners; and an attitude survey with Likert-scale rated items regarding the pre-service teachers' implementation of creative arts activities in their classrooms. Independent samples $t$-tests and paired differences tests were conducted to determine the differences between the candidates' pre-post self-efficacy mean scores; between their rating scale scores, and between their attitude survey results. Qualitative data consisted of written reflections, interviews, and instructors' field notes, Creative Arts lesson plans, and open-ended responses on the attitude survey. The data was coded and organized to reveal recurring themes. 


\section{Results}

Quantitative results revealed a significant difference between the pre-and post-scale general teacher self-efficacy ratings (see Table 1). The statements on the survey specifically related to their self-efficacy for meeting needs of diverse learners included items \#5-9: (5) getting through to the most difficult student, (6) promoting learning when there is lack of support from the home, (7) keeping students on task on difficult assignments, (8) increasing students' memory of what they have been taught in previous lessons (significance indicated), and (9) motivating students who show low interest in schoolwork (see Table 2).

Table 1. Pre- and Post- S.E. Scale Ratings

\begin{tabular}{|c|c|c|c|c|c|c|}
\hline & \multicolumn{3}{|c|}{ Paired Differences } & \multirow[b]{2}{*}{$t$} & \multirow[b]{2}{*}{ df } & \multirow[b]{2}{*}{$\begin{array}{c}\text { Sig. } \\
\text { (2-tailed) }\end{array}$} \\
\hline & Mean & $\begin{array}{c}\text { Std. } \\
\text { Deviation }\end{array}$ & $\begin{array}{c}\text { Std. Error } \\
\text { Mean }\end{array}$ & & & \\
\hline $\begin{array}{l}\text { Pre-Post } \\
\text { Assessment }\end{array}$ & -.36 & .81 & .17 & -2.18 & 23 & .04 \\
\hline
\end{tabular}

Source: Arrington (2017).

Table 2. Comparison of Means - S.E. Meeting Diverse Needs

\begin{tabular}{ccccccc}
\hline Statement & Mean & $\begin{array}{c}\text { Std. } \\
\text { Deviation } \\
5\end{array}$ & $\begin{array}{c}\text { Std. Error } \\
\text { Mean }\end{array}$ & $\boldsymbol{t}$ & df & $\begin{array}{c}\text { Sig. (2 } \\
\text { tailed) } \\
\text { (a) }\end{array}$ \\
\hline 6 & -.04 & 1.23 & .25 & -.17 & 23 & .870 \\
\hline 7 & -.29 & 1.00 & .20 & -1.43 & 23 & .166 \\
\hline 8 & -.04 & 1.33 & .27 & -.15 & 23 & .880 \\
\hline 9 & -.63 & .92 & .19 & -3.32 & 23 & .003 \\
\hline $\mathrm{P}<.05$ & -.08 & 1.02 & .21 & .40 & 23 & .692 \\
\hline
\end{tabular}

Source: Arrington (2017)

Students rated their attitude toward the effects of implementing their music-based activities. First, they considered sharing their activities with peers in class versus implementing the activities with their K-2 students, and then they rated the level of the activities' contribution to their (a) efficacy for meeting the needs of diverse learners in their classroom, (b) understanding of integration of creative arts in the elementary classroom, and (c) efficacy for integration of creative arts in the elementary classroom. Only two students indicated that sharing with peers contributed most to the above-named criteria. Seventeen students indicated that implementing with peers and K-2 students contributed equally to their understanding of and efficacy for integration of creative arts, whereas only 9 indicated that they equally contributed to efficacy for meeting needs of diverse learners. Fifteen responded that implementing with their K-2 students provided most efficacy for meeting 
needs of diverse learners and less than seven indicated that K-2 implementation contributed to understanding of and efficacy for creative arts implementation. See Figure 1. Additionally, students rated their attitude toward the implementation of their music-based, or similar, activities in future classrooms. One student indicated that he/she was very unlikely to implement, but eighteen indicated that they were very likely to use similar project in their future classrooms (see Figure 2).

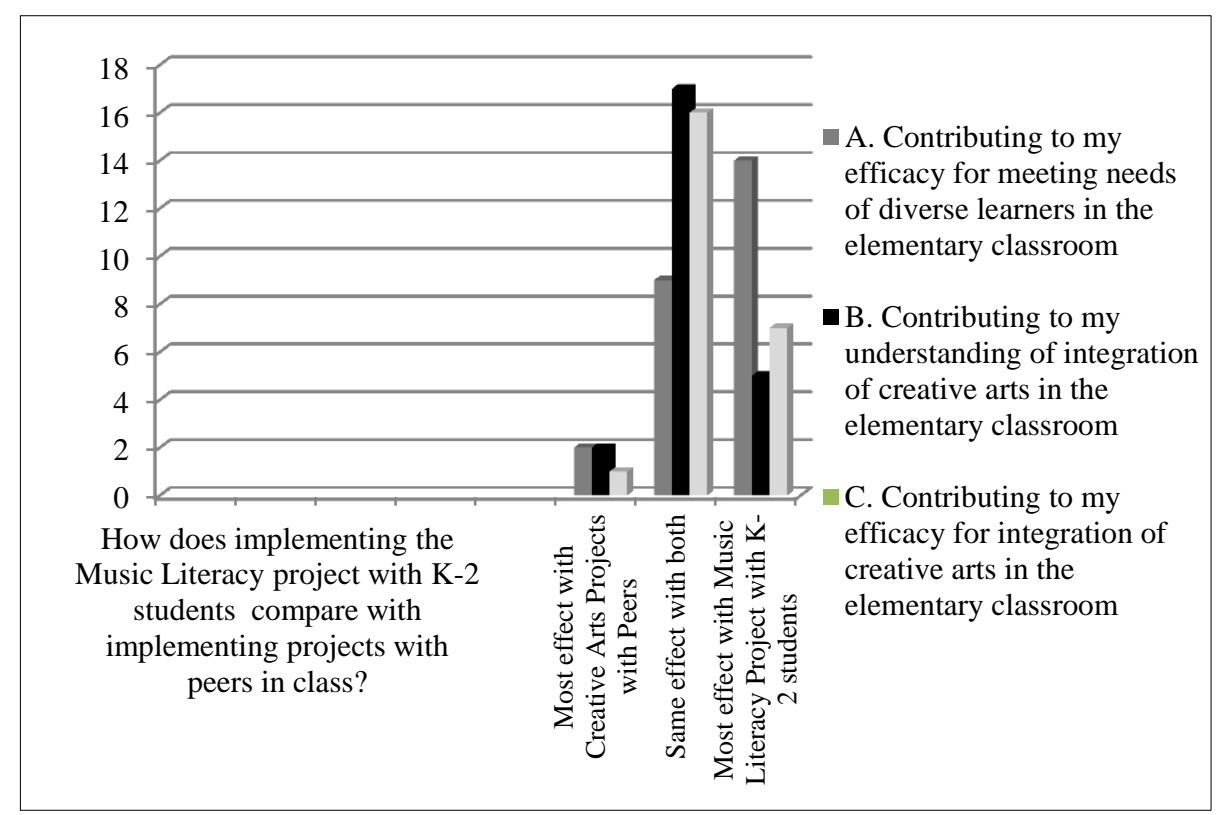

Figure 1. Attitude toward Contributions of Music Literacy Project. Source: Arrington (2017) 


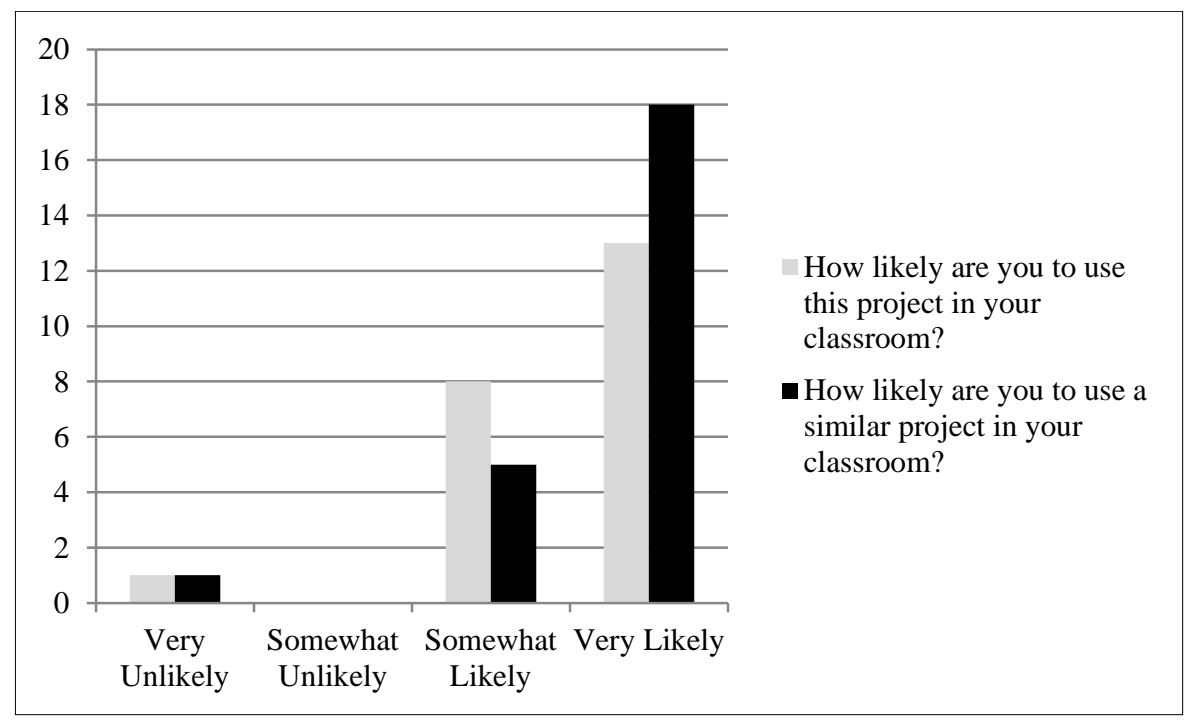

Figure 2. Attitude toward Implementation of Music Literacy Projects in Future Classrooms. Source: Arrington (2017)

In the qualitative analysis, reflections and open-ended responses were coded. Three major themes emerged, as follows: (a) pre-service teachers' learning experience, (b) diverse learners' learning experience, and (c) behavior management. Excerpts are provided (see Figure 3). 


\section{THEME: Pre-Service Teacher Learning}

"It was hard work putting this together and setting this up. But it was worth it. It made me realize that with a little extra time and planning, music can be integrated into other curricular areas and the students can learn a lot from it..." (PST\#1).

"It definitely helped me see the importance of using creative arts in the classroom" (PST\#2).

"[I saw] firsthand by being involved that you can teach content in different ways..." (PST\#2).

"I think this activity showed me to think outside the box when planning..." (PST\#4).

"It also made me think of different aspects of creative arts that could be used to help diverse learners, especially if they are more drama filled or movement/dance filled. It would work best to incorporate all aspects of creative arts in the classroom..." (PST\#6).

"It made me want to incorporate music into my lessons more often..." (PST\#8).

"I really liked that we were able to do this with our elementary class instead of trying it on our fellow classmates. It gave me a better idea of how it would be if I used it in my future classroom" (PST \#11).

"I am very happy that I had to do this music literacy lesson...I have never really enjoyed music or wanted to teach with it but after the lesson I will definitely be doing it more often..." (PST\#9).

\section{THEME: Diverse Student Learning}

"This activity impacted the diverse learners by keeping their interest and it gave them something to do hands on, which really helped them stay focus [sic] and on task" (PST\#3).

"During this lesson students needed to pay special attention to their specific roles, listening carefully for their cues to play their instrument. Specific students were assigned certain instruments for a reason. ... all students were able to stay engaged during the lesson as everyone was actively listening for their assigned cue...by hearing the sounds and seeing the motions, both visual and auditory learners were able to more closely follow along with the story, thus aiding their comprehension..." (PST\#9).

"I have a class that normally misbehaves a lot. But conducting this activity got everyone involved and they loved it. I was actually shocked at how well they all participated" (PST\#2).

"I think doing activities like this can really help you get your students involved and actually want to participate" (PST\#3).

After hearing "Wow, this is fun!" and "I wish we could do this a lot more," I realized the impact that the instruments had on their interest and overall participation and comprehension..." (PST\#5).

\section{THEME: Behavior Management}

This lesson had the potential to go horribly wrong. I was very nervous to give a group of six year olds musical instruments, but with a well thought out behavior management plan and a little enthusiasm I was surprised at how well it went (PST\#9).

I loved watching the students during this activity...At first I was rather apprehensive, thinking I would have a hard time controlling the students while they all were playing. However, the lesson far exceeded my expectations. Every student had a smile on their face during the lesson....it was so lovely to see (PST\#10).

Figure 3. Themes from Student Reflections. Source: Arrington (2017) 


\section{Discussion}

During their self-reflections, the pre-service teachers indicated they will utilize their arts lessons or similar activities in their future placements and classrooms. Traditionally, some had been hesitant to "think outside the box" to integrate the arts-sometimes due to lack of confidence or experience in the arts, or sometimes due to a perceived lack of time during their lessons. Although these pre-service teachers are not expected to teach music at the level of a specialist, they are able to use experience and knowledge gleaned in their university course-working with the music standards and making connections with common skills of literacy and music such as processing, decoding, and analyzing (Weidner, 2013). As a result of this project, the pre-service teachers have indicated a higher level of self-efficaciousness for implementing these types of experiences in their future lessons.

Tomlinson (2015) reminds us that the "nature of 21st century students will require classroom teachers to be more responsive to the "broadening array of cultures, languages, experiences, economics and interests represented in most contemporary classrooms..." (p. 203). A major component of this project addressed how the arts can be used to accommodate diverse learning styles in their classrooms. As evident in the pre-service teachers' Creative Arts lesson plans, they are becoming more experienced in assessing their students' needs and in planning a variety of developmentally appropriate activities to address those needs. Based on the reflections of successful experiences during the music integration lessons, this project has enriched pre-service teachers' planning and teaching in both courses--Creative Arts and their first Practicum Course.

As our teacher education program continues to prepare our pre-service teachers for their upcoming certification requirement during student teaching-edTPA, a student teacher performance assessment developed by the Stanford Center for Assessment, Learning and Equity - there will be more emphasis in our program on the intense reflective component. Inasmuch as reflection was a vital component of this experience, the pre-service teachers will be better prepared to reflect on their experience at a level exemplary of teachers who are prepared for teaching all students (AACTE, 2013). Drawing from success with their music integration lessons, our teaching candidates will be better prepared to teach ALL students - being able to identify and accommodate their K-2 students' diversities, and becoming more self-efficacious in the process. 


\section{References}

American Association of College Teacher Educators (AACTE). (2013). About edTPA. Retrieved from http://edtpa.aacte.org

Arrington, N. M. and Lu, H-S. (2015). Assessing our students assessing their students: Examining support and impact of preservice teachers on P-5 student learning. The Teacher Educator, 50(1), 9-30.

Bandura, A. (1997). Self-efficacy: The exercise of control. NewYork: Freeman.

Bandura, A. (2006). Guide for constructing self-efficacy scales. In F. Pajares and T. Urdan (Eds.), Self-efficacy beliefs of adolescents (307-337). New York: Information Age Publishing. Retrieved from http://www.des.emory.edu/mfp/self-efficacy. html\#instruments

Bernstorf, E. (2013, Fall). Reading acquisition in music and language: The cry for preschool music endures. Kodaly Envoy, 24-28.

Coleman, D. (n.d.). Guiding principles for the arts grades K-12. Retrieved from http://www.aep-arts.org/resources-2/common-core-and-the-arts/

Common Core Standards State Initiative (CCSS). (2012). Implementing the common core state standards. Retrieved from www.corestandards.org

Gardner, H. (1993). Frames of mind: The theory of multiple intelligences. New York: Basic Books

Hansen, D. \& Bernstorf, E. (2002). Linking music learning to reading instruction. (Cover story). Music Educators Journal, 88(5), 17.

Hutchings, P., \& Cambridge, B. (1999). Your invitation to participate in the Carnegie Teaching Academy Campus Program. Washington, DC: American Association for Higher Education and the Carnegie Foundation for the Advancement of Teaching.

Isbell, R. \& Raines, S. (2013). Creativity and the arts with young children. Belmont, CA: Wadsworth Cengage Learning.

National Association for Music Education (NAfME). (2014). National standards for music education. Retrieved from http://musiced.nafme.org/resources/national-standards-formusic-education/

Paquette, K. R. \& Rieg, S. A. (2008), Using music to support the literacy development of young English language learners. Early Childhood Education Journal, 36, doi: 10.1007/s10643-008-0277-9

Tomlinson, C. A. (2015). Teaching for excellence in academically diverse classrooms. (Published Online) Symposium: $21^{\text {st }}$ Century Excellence in Education, Part 2. Doi 10.1007/s12115-015-9888-0

Weidner, B. N. (2013). Supporting common core reading literacy in the music performance classroom. The Illinois Music Educator. (73)3, 55-59. 